\title{
CONSEQÜÊNCIAS DA ALTERAÇÃO DA VAZÃO SOBRE ALGUNS PARÂMETROS DE QUALIDADE DE ÁGUA FLUVIAL
}

\author{
Elenice Fritzsons ${ }^{1}$ \\ Eduardo Chemas HindiI2 \\ Luiz Eduardo Mantovani3 \\ Nivaldo Eduardo Rizzi4
}

\begin{abstract}
RESUMO
A variação na qualidade de água depende do regime hidrológico do rio, principalmente da variabilidade do deflúvio. Este trabalho foi conduzido na bacia hidrográfica do Alto Capivari, localizada $20 \mathrm{~km}$ ao norte da Região Metropolitana de Curitiba, Estado do Paraná, Brasil. Foram analisados e comparados dados diários de qualidade de água e de vazão de 1998 a 1999. Os resultados mostram que a qualidade das águas sofreram grande variação com a vazão, principalmente em relação a alguns parâmetros de qualidade, tais como turbidez, $\mathrm{pH}$, alcalinidade, cor e matéria orgânica. Esta alta variabilidade foi relacionada ao deflúvio por meio de coeficientes correlação. As correlações encontradas foram fortes, denotando uma tendência, quando comparados intervalos de vazão com a média dos valores médios dos parâmetros. Com exceção do $\mathrm{pH}$ e alcalinidade, todos os parâmetros tiveram seus valores elevados quando há aumento na vazão, o mesmo ocorrendo com o desvio padrão.

Palavras Chave: qualidade de água, vazão, monitoramento
\end{abstract}

\begin{abstract}
Water quality variability depends on the hydrological regime of the river or stream, meanly water discharge variability. This work was carried out in the Alto Capivari basin, located $20 \mathrm{~km}$ northern part of Curitiba's Metropolitan Region, Paraná state, Brazil. Daily dates of quality water and water discharge from 1998 to 1999 were analyzed and compared. The results reveal that the stream water quality varies significantly with discharge mainly for turbidity, alkalinity, $\mathrm{pH}$, color and organic matter. This high variability was linked to discharge by means of coefficient of correlation. The results indicate a good correlation while comparing the discharge intervals in the stream with average of the studied parameters. With exception of $\mathrm{pH}$ and alkalinity, all parameters increased with increasing the discharge and it occurred with standard deviation.
\end{abstract}

Key Words: water quality, stream flow, monitoring

\section{INTRODUÇÃO}

Ao contrário dos oceanos, que apresentam composição química praticamente semelhante em todo o lugar do mundo e há milênios mantêm um mesmo valor de $\mathrm{pH}$, a composição das águas dos rios é muito variável. Esta variação, mesmo em ambientes completamente naturais, é determinada por diversos fatores: clima (temperatura, umidade, ventos, precipitação), tipos de rochas, vegetação, contribuição da água subterrânea, composição da água da chuva e flutuações de vazão.
O conhecimento da alteração da qualidade de água de um sistema lótico frente às variações de vazão é muito importante, não somente para estações de tratamento de água que, em geral, nos períodos chuvosos necessitam tratar água de pior qualidade, utilizando maior quantidade de produtos químicos, mas também para registrar o comportamento de um rio numa determinada época. Este comportamento é relevante, uma vez que reflete as condições ambientais da bacia hidrográfica, pois, como afirma Margalef (1983), através da qualidade de água de um rio

\footnotetext{
${ }^{1}$ Agrônoma, Doutora em Eng. Florestal; e-mail: elenicefrt@uol.com.br

${ }^{2}$ Geólogo, Mestre em Geologia pela UFPR e Pesq. do Laboratório de Pesquisas Hidrogeológicas (LPH/UFPR)

${ }^{3}$ Geólogo, Doutor em Geologia, Prof. do curso de Geologia da UFPR/ e-mail: lem@ufpr.br

${ }^{4}$ Eng. Florestal, Doutor em Saneamento Ambiental, Prof.do curso de Eng. Florestal da UFPR; e-mail: niva@ floresta.ufpr.br
} 
pode-se estimar a integridade da bacia hidrográfica de origem.

Estudos conduzidos em ambientes preservados nos EUA mostram a concentração iônica sendo pouco alterada (menos de 2 vezes), num fluxo variando muito mais que 4 ordens de magnitude, considerando o ciclo anual (Chapman \& Kimstack, 1992). No Brasil, trabalhos de Arcova et. al. (1998), estabelecem relações entre uso e ocupação das terras, inclusive de áreas florestadas, e a qualidade de água, no âmbito de bacias hidrográficas.

A precipitação é um fenômeno meteorológico que exerce influencia na vazão e na qualidade de um corpo d'água. Entretanto, especialmente no meio rural, é difícil estabelecer uma relação direta entre precipitação e qualidade de água, uma vez que diferentes intensidades de precipitação ocasionam diversos níveis de impactos no solo, iniciando processos erosivos de graus variáveis, de acordo com a interação desta precipitação com terrenos sob diversos usos e ocupações. Por outro lado, a influência da precipitação sobre a vazão deve ser analisada dentro de uma seqüência de eventos pluviométricos, uma vez que o grau de saturação do solo e do sistema freático influenciam diretamente na taxa de escoamento superficial.

Assim, o estudo da vazão parece ser, em geral, mais adequado na avaliação da alteração da qualidade de um corpo de água do que a precipitação. Também é conhecido que, com os dados de vazão, pode-se estimar as variáveis qualitativas, pelos padrões de concentração com o deflúvio, por exemplo, o teor de sólidos solúveis, turbidez, matéria orgânica, etc. (Allan, 1995; Souza, 1996). Meybeck et al. (1989) $)^{5}$, citados por Meybeck et al. (1992), apresentam vários gráficos que ilustram curvas de concentração de várias substâncias com o deflúvio, sendo que tais curvas podem representar escalas que variam desde um simples evento de precipitação até tendências plurianuais.

\footnotetext{
${ }^{5}$ MEYBECK, M. e HELMER, R. The quality of rivers: form pristine stage to global pollution. Paleogeogr., Palaeoclimatol., Palaeoecol. (Global Planet. Change Sect.) 1989, 75, 283-309.
}

SUDERHSA - Superintendência de Desenvolvimento de Recursos Hídricos e Saneamento Ambiental - (1997), verificou que, no aumento da vazão em períodos de chuvas, alguns rios de algumas bacias do Paraná diminuíam sua qualidade, avaliados pelo IQA, devido a uma elevação da DBO, DQO, nitrogênio e coliformes fecais. Este fato foi registrado na bacia dos Rios das Cinzas, Ivai, Pirapó, Ribeira e em dois pontos na bacia do Tibagi. A tabela 1 mostra dois rios da bacia do rio das Cinzas, com diferentes vazões e conseqüente alteração na qualidade da água.

Entretanto, nos rios que recebem efluentes de áreas rurais e urbanas, a qualidade de água pode piorar com a estiagem pela diminuição de vazão, e conseqüentemente, do efeito de diluição, concentrando poluentes, como demonstraram Da Silva e Sacomani (2001), em trabalho realizado no rio Pardo, Botucatu, Estado de São Paulo.

Neste contexto, este estudo tem por objetivo principal compreender a influência da alteração do deflúvio em alguns parâmetros de qualidade de água no rio Capivari, procurando definir um comportamento dos mesmos. Por objetivo secundário, fornecer indicativos de conservação da bacia do Alto Capivari quanto ao seu grau de conservação, através da analise da qualidade de água. 
Tabela 1: Parâmetros de qualidade de água relacionados à variação de vazão

Table 1: $\quad$ Parameters of water quality related to water discharge variation

\begin{tabular}{lcccc}
\hline PARÂMETROS & \multicolumn{3}{c}{ ESTAÇÕES } \\
\cline { 2 - 4 } & \multicolumn{2}{c}{ Rio das Cinzas-Tomazina } & \multicolumn{2}{c}{ Rio Laranjinha-Santa Terezinha } \\
Q $\left(\mathrm{m}^{3} / \mathrm{s}\right)$ & $31 / 07 / 91$ & $10 / 03 / 92$ & $20 / 11 / 91$ & $17 / 03 / 92$ \\
DBO (t/dia) & 14,4 & 23,9 & 20,0 & 77,6 \\
DQO (t/dia) & 1,2 & 4,1 & 3,5 & 13,4 \\
N-KJEL (t/dia) & 2,5 & 16,5 & 10,4 & 60,3 \\
COLI-FE (NMP/dia) & 0,5 & 1,0 & 0,9 & 3,3 \\
\hline
\end{tabular}

Q: vazão; DBO: demanda bioquímica de oxigênio; DQO: demanda química de oxigênio; N-KJEL: $\mathrm{N}$ total; COLI-FE: Coliformes fecais

Fonte: SUDERHSA (1997)

\section{MATERIAL}

Este trabalho foi desenvolvido na bacia hidrográfica do Alto Capivari, localizada na área rural ao norte da região urbana de Curitiba, a qual apresenta como rio principal o rio Capivari, pertencente à bacia do Ribeira do Iguape, no conjunto do Atlântico Leste. O clima se caracteriza como $\mathrm{Cfb}$, baseado na classificação de Köeppen, com pluviometria média de $1400 \mathrm{~mm}$ e evapotranspiração em torno de $800 \mathrm{~mm}$, não apresentando, em média, estação seca (Maack, 1986). A região também pertence ao Primeiro Planalto Paranaense e geologicamente ao denominado carste paranaense, apresentando, em termos médios, em grande parte de sua área, substrato de rochas carbonáticas, dispostas em faixas acompanhadas de filitos, quartzitos, cortados por diques de doleritos. A figura 1 apresenta a localização da bacia.

A bacia apresenta um formato bastante irregular e nela predominam pequenas unidades de agricultura familiar produtoras de hortaliças, milho e feijão e alguns poucos animais criados para consumo próprio. Em termos de vegetação, predominam sistemas secundários de ocupação e fragmentos florestais. A atividade mineradora se faz presente através da extração de metadolomitos que vem se expandindo nos últimos anos e constitui uma importante atividade econômica do município.

A vegetação natural corresponde ao domínio da Floresta Ombrófila Mista (FOM), ou floresta com araucária, a qual é exclusiva do Planalto Meridional Brasileiro. Klein e Hatschback (1962), em estudo de fitofisionomia, que abrange esta bacia, baseado num levantamento florístico de 1952, concluíram que os remanescentes da Floresta Ombrófila Mista, já eram raros e perturbados pela intervenção humana.

O ponto de coleta de dados de água ocorreu no rio Capivari, na altura da ETA (Estação de tratamento de água) de São Dimas, município de Colombo e distrito de Várzea do Capivari. Esta ETA pertence à SANEPAR (Companhia de Saneamento do Paraná), tendo iniciado suas atividades em 1986 e encerrado em 2000, com a substituição da captação das águas superficiais do rio Capivari, pela extração de águas subterrâneas.

Para o desenvolvimento deste trabalho, foram identificados e relacionados dois tipos de dados: os dados diários do boletim de tratamento de água da SANEPAR referentes aos meses de janeiro de 1998 a dezembro de 1999 e os dados diários de vazão da estação fluviométrica da Chácara da Luz (Código DNAEE: 8129100), do mesmo período. A Chácara da Luz dista 200 metros a jusante da ETA São Dimas. Estas estações estão situadas nas coordenadas geográficas: $25^{\circ} 25^{\prime}$ latitude $\mathrm{S}$, $49^{\circ} 09^{\prime}$ longitude $\mathrm{W}$, altitude de $870 \mathrm{~m}$.

Com exceção do mês de março de 1999, foram totalizados 698 dias de amostragens, sendo que os dados de qualidade de água envolveram os seguintes parâmetros: alcalinidade, turbidez média, matéria orgânica, pH médio e cor verdadeira. Deve-se observar que a turbidez, a cor e $\mathrm{pH}$ foram o resultado de uma média de, no mínimo, 15 amostragens diárias, uma vez que as amostragens são feitas de hora em hora, e que a ETA não trabalhou menos de 15 horas por dia durante este período. 


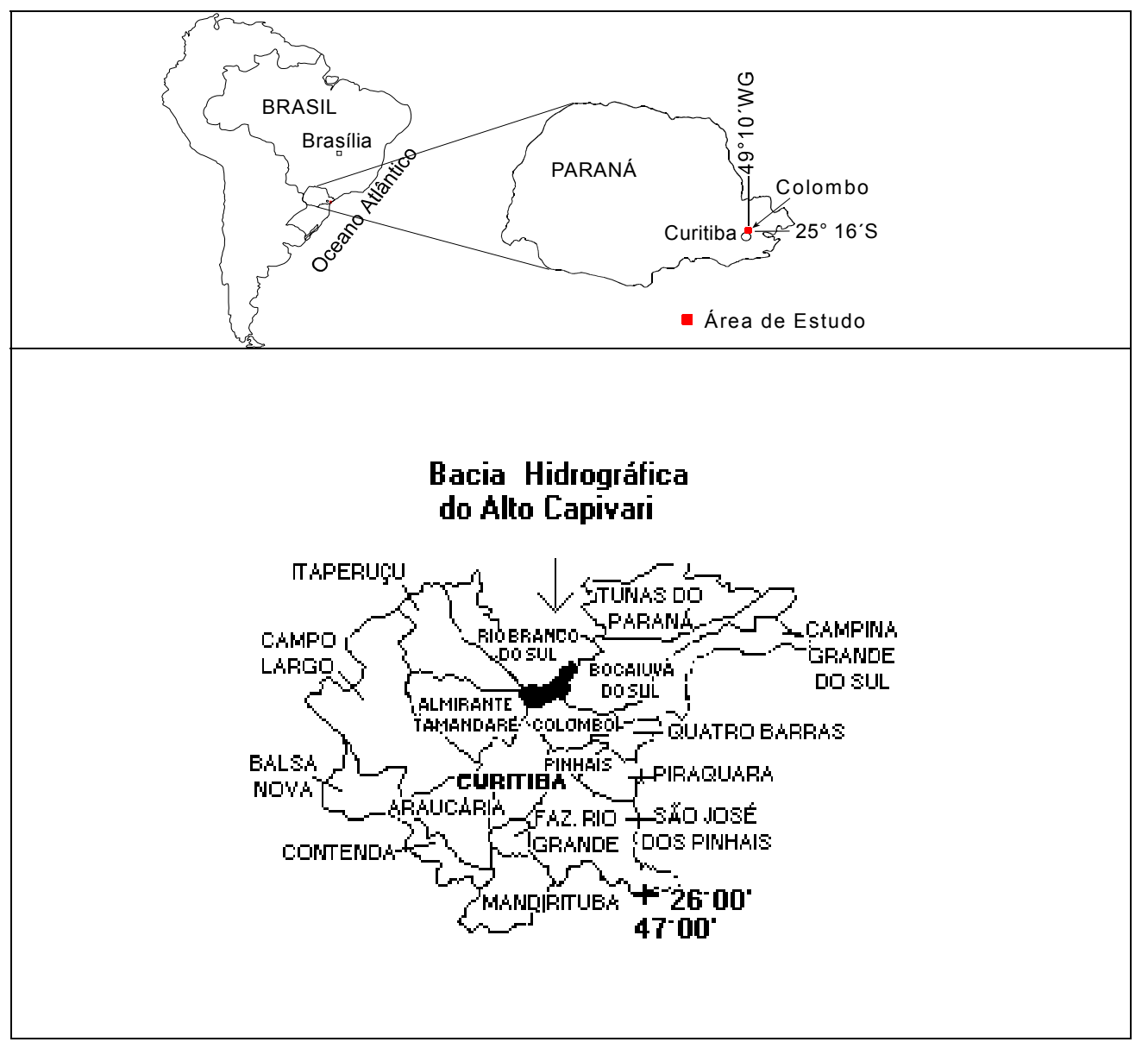

Figura 1: Localização da bacia do Alto Capivari

Figure 1: Localization of Alto Capivari basin

\section{MÉTODOS}

Inicialmente, a bacia hidrográfica foi delimitada em carta planialtimétrica, escala 1:20.000, com auxílio de fotos aéreas pancromáticas em escala 1:60.000, de 1996, tendo sua área obtida. Para melhor diagnosticar a qualidade de água da bacia, inicialmente algumas análises estatísticas descritivas foram efetuadas com os dados dos 698 dias amostrados, obtendo-se a média, mediana e desvio padrão, para cada parâmetro (alcalinidade, turbidez, matéria orgânica, $\mathrm{pH}$, e cor).

Os dados de vazão dos anos de 1998 e 1999 foram comparados diariamente com alguns parâmetros de qualidade de água, sendo que gráficos de dispersão foram construídos para melhor visualização e compreensão do comportamento dos parâmetros em diferentes vazões.
A fim de se obter uma tendência no comportamento de cada parâmetro frente à alteração do deflúvio, a vazão foi classificada em ordem crescente e separada por intervalos de $1 \mathrm{~m}^{3} / \mathrm{s}$. Com os valores dos parâmetros dentro de cada intervalo, foi composta uma média correspondente ao valor de cada parâmetro no intervalo. Com estes valores médios nos intervalos de vazão, foram construídos gráficos de linha para cada parâmetro. Em cada gráfico, ajustou-se uma linha de tendência linear. Estas linhas de tendência são usadas para o estudo de problemas de previsão, também chamados de análise de regressão.

Para cada linha de tendência, obtevese a fórmula da equação linear correspondente com o valor do coeficiente de determinação ( $R$ quadrado) respectivo. Este coeficiente é um indicador que varia de 0 a 1 e revela a proximidade dos valores estimados da linha de 
tendência em correspondência com os dados verdadeiros. Uma linha de tendência é mais confiável quando o valor de $\mathrm{R}$ quadrado é igual ou próximo a 1 .

Considerou-se o intervalo apenas até $6,99 \mathrm{~m}^{3} / \mathrm{s}$, devido ao número reduzido de amostras acima deste valor. Obteve-se também o desvio padrão de cada parâmetro nos intervalos de vazão considerados para se avaliar a dispersão.

A título de visualização das distribuições das freqüências das vazões nos intervalos, foi composta a tabela 2 , onde os valores estão distribuídos da seguinte forma: entre 0 a $0,99 \mathrm{~m}^{3} / \mathrm{s}$ ocorreram 17 medições, entre 1 a $1,99 \mathrm{~m}^{3} / \mathrm{s}, 115$, assim por diante.

Tabela 2: Distribuição da freqüência das amostras nos intervalos de vazão (rio Capivari, 1998 a 1999)

Table 2: Frequency distribution of the samples in the water discharge intervals (Capivari stream, 1998 to

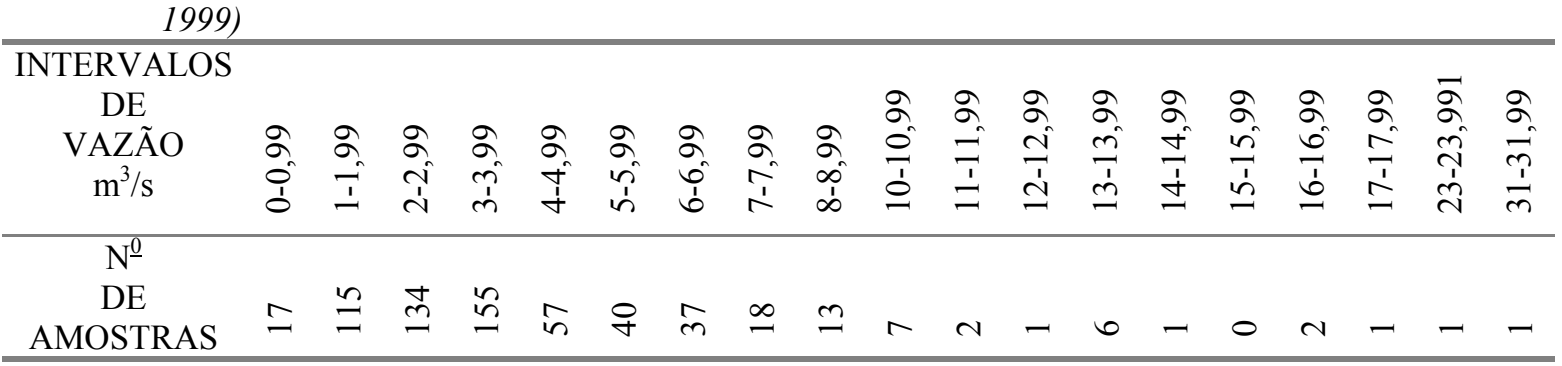

\section{RESULTADOS E DISCUSSÃO}

A área obtida da bacia hidrográfica estudada foi de $126 \mathrm{~km}^{2}$, com dois rios principais, rios Bacaetava e Capivari, sendo o primeiro um afluente do segundo.

Tabela 3: Amplitude, média, mediana, desvio padrão e coeficiente de correlação para os parâmetros (rio Capivari, de 1998 a 1999)

Table 3: Range, mean, medians, standard deviation and coefficient of correlation for parameters (Capivari stream, from 1998 to 1999)

\begin{tabular}{lllllll}
\hline \multicolumn{1}{c}{ Parâmetros } & Unidades & Amplitude & Média & Mediana & Desvio padrão & $\begin{array}{c}\text { Coeficiente de } \\
\text { correlação* }\end{array}$ \\
\hline Alcalinidade & $\mathrm{mg} / \mathrm{l}$ & 32 a 110 & 92,5 & 97,0 & 12,8 & $-0,68$ \\
Matéria orgânica & $\mathrm{mg} / 1$ & 2,2 a 11,9 & 4,4 & 3,8 & 1,8 & 0,68 \\
pH médio & & 7,45 a 9,2 & 8,2 & 8,3 & 0,2 & $-0,21$ \\
Cor média & $\mathrm{uH}$ & 10,8 a 1400 & 167,0 & 77,5 & 198,0 & 0,62 \\
Turbidez média & $\mathrm{UNT}$ & 4,6 a 202 & 29,2 & 14,8 & 33,8 & 0,70 \\
Vazão & $\mathrm{m}^{3} / \mathrm{s}$ & 0,46 a 31,27 & 3,7 & 3,1 & 2,8 & $\mathrm{x}$ \\
\hline Oazo
\end{tabular}

Obs: * coeficiente de correlação entre a vazão e o parâmetro analisado.

Quanto à vazão, pode-se observar nesta tabela, que o rio Capivari, no trecho estudado, apresenta grande amplitude na vazão, chegando a valores mínimos de 0,46 $\mathrm{m}^{3} / \mathrm{s}$ em época de forte estiagem a valores máximos de $31,27 \mathrm{~m}^{3} / \mathrm{s}$, sendo a vazão média do período de $3,7 \mathrm{~m}^{3} / \mathrm{s}$.
A tabela 3 apresenta a amplitude média, mediana, desvio padrão da alcalinidade, matéria orgânica, $\mathrm{pH}$, turbidez média, cor média e vazão dos dados coletados. 
Tabela 4: Porcentagem média de escoamento direto / precipitação e vazão específica (bacia do Alto Capivari, de 1997 a 1999)

Table 4: Average percentage of direct draining/precipitation and specific water discharge (Alto Capivari basin, from 1997 to 1999).

\begin{tabular}{|c|c|c|c|c|c|c|}
\hline ANO & $\begin{array}{c}\text { PP } \\
\text { ANUAL } \\
(\mathrm{mm})\end{array}$ & $\begin{array}{l}\text { Q } \\
\text { MÉDI } \\
\text { O } \\
\left(\mathrm{m}^{3} / \mathrm{s}\right)\end{array}$ & $\begin{array}{c}\text { \% MÉDIA DE } \\
\text { ESCOAMENT } \\
\text { O } \\
\text { DIRETO }\end{array}$ & $\begin{array}{l}\text { ESCOAMENT } \\
\text { O DIRETO / } \\
\text { PRECIPITAÇÃ } \\
\text { O }\end{array}$ & $\begin{array}{c}\text { \% DE "PERDA" } \\
\text { (EVAPOTRANSPIRAÇ } \\
\text { ÃO MAIS } \\
\text { INFILTRAÇÃO) }\end{array}$ & $\begin{array}{c}\mathrm{Q} \\
\text { ESPECÍFIC } \\
\mathrm{A} \\
\left(1 / \mathrm{s} / \mathrm{km}^{2}\right)\end{array}$ \\
\hline 97 & 1468,44 & 2,92 & 50 & 0,50 & 50 & 22,60 \\
\hline 98 & 1975,16 & 4,27 & 54 & 0,54 & 46 & 33,05 \\
\hline 99 & 1468,63 & 3,05 & 52 & 0,52 & 48 & 23,60 \\
\hline MÉDIA* & 1637,41 & 3,41 & 52 & 0,52 & 48 & 26,42 \\
\hline
\end{tabular}

NOTA: * média resultante dos três anos.

Fonte: FRITZSONS (2003)

Assim, para a bacia do Alto Capivari, o escoamento médio superficial é bastante alto, justificando a resposta rápida da vazão frente à precipitação, ilustrado pela figura 2 , onde os picos de precipitação são coincidentes aos picos de vazão. Este escoamento é superior ao da média do Estado, que é de 42\% (Jica, 1995), e superior à média encontrada para a bacia do
Ribeira. Isto pode ser justificado pela altitude elevada condicionando menores temperaturas, maior umidade relativa média do ar e conseqüente menor taxa de evapotranspiração, o que atenua o déficit hídrico nos solos, e também pelo relevo mais acidentado, típico das áreas destas nascentes, como é o caso da bacia do Alto Capivari.

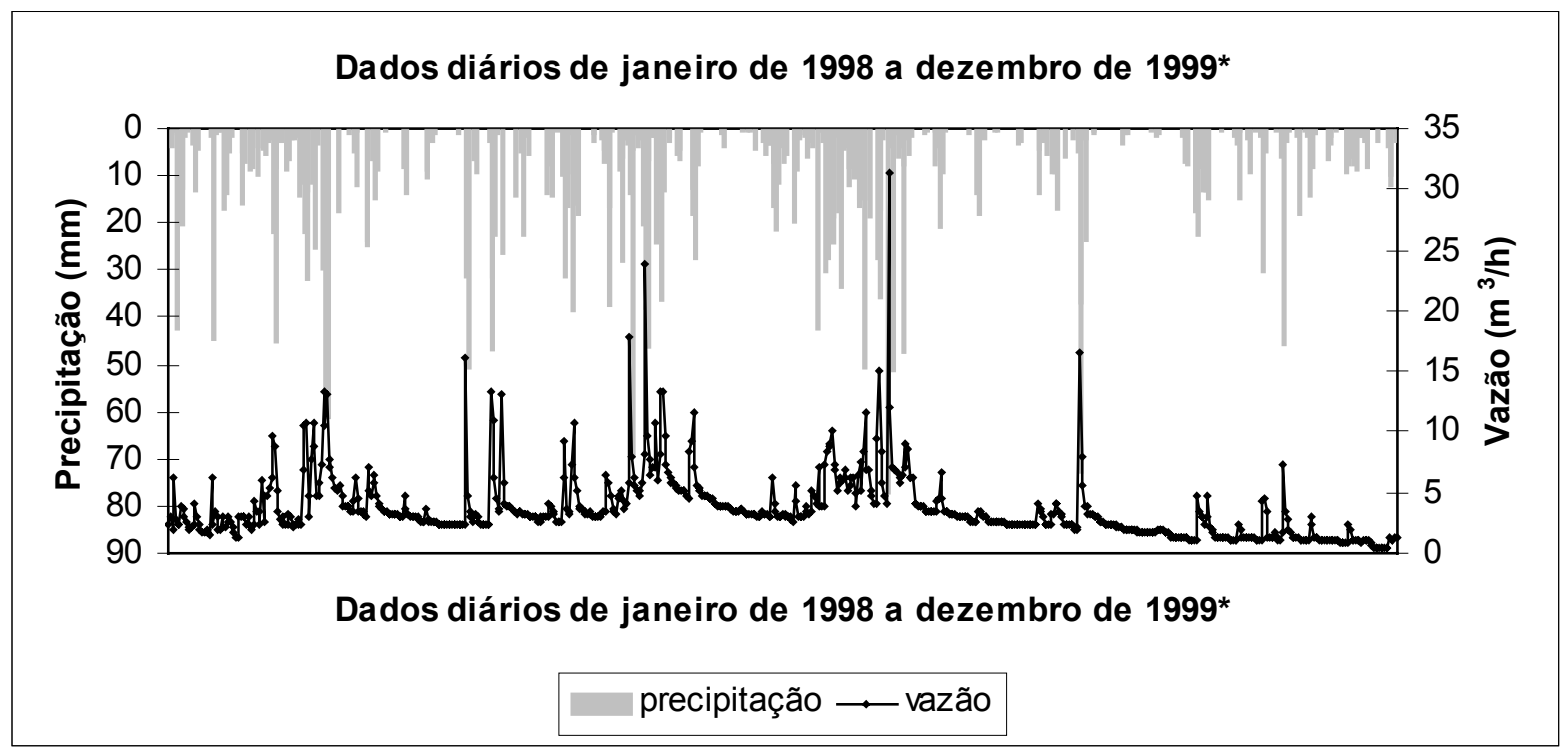

Figura 2: Relação entre precipitação e vazão (rio Capivari, de 1998 a 1999)

Figure 2: Relation between precipitation and water discharge (Capivari stream, from 1998 to 1999) Nota*: dados diários excetuando o mês de março de 1999.

Analisando a carta geológica, observase também que uma boa parte da área se encontra sob litologias que favorecem o escorrimento superficial em detrimento da infiltração, tais como filitos mais impermeáveis, a exemplo dos que ocorrem na sub-bacia do Campestre, além dos gnaisses e granitos do embasamento cristalino e de rochas carbonáticas pouco carstificadas.

Quanto a turbidez e cor, os valores presentes na tabela 3 são muito elevados, sendo que os níveis encontrados ultrapassam os limites estabelecidos pelo CONAMA 20/86 (1992) até para a classe 3, ou seja, para as águas brutas destinadas ao abastecimento e 
também para irrigação de hortaliças e plantas frutíferas e mesmo para o critério de "satisfatório" para balneabilidade, isto se a análise fosse realizada de forma sistemática, como recomendado por esse orgão ${ }^{6}$. Entretanto, estes altos teores apresentados, o forte coeficiente de correlação com a vazão e alta variabilidade denotam problemas de degradação da bacia estudada, seja por falta da floresta ciliar e, ou, associado aos inadequados uso e ocupação das terras.

Quanto à cor, a alteração desta na água pode ocorrer por contaminação mineral ou vegetal, sendo que as substâncias dissolvidas refletem o que se chama de cor verdadeira, o que, em conjunto com os colóides, produz o que se denomina cor aparente. Assim, a diferenciação entre a cor verdadeira (medida em escala Hazen-uH) e a cor aparente, a qual é adicionada pela turbidez, é dada pelo tamanho das partículas (Bittencourt e Hindi, 2000).

Em termos ambientais, para Branco (1987), a principal conseqüência da alteração da cor e turbidez num corpo d'água é a redução da penetração da luz solar e conseqüente diminuição da taxa fotossintética, prejudicando a oxigenação do meio, principalmente em águas paradas ou mesmo em rios de baixa turbulência.

De acordo com o CONAMA 20/86 (1992), a cor para as águas das classes 2 e 3 poderá chegar a $75 \mathrm{uH}$ (Unidades Hazen), para as demais não há restrições. A cor média obtida nesta amostragem foi de $167 \mathrm{uH}$, demonstrando uma alta carga de substâncias dissolvidas nas águas do rio Capivari.

Quanto ao $\mathrm{pH}$, a média de 8,2 é bastante alta para águas naturais brasileiras, atingindo um máximo de 9,2, acima do tolerado para os rios da classe 3, do CONAMA 20/86 (1992), cujo limite superior é de 9. Este padrão incomum pode ser indício da forte atividade mineradora da bacia, que consiste na extração de metadolomitos próximo ao leito do Rio Bacaetava, principal afluente do rio Capivari. A existência destas pedreiras, além de fornos de cal, que lançam nos rios e no ar material calcário finamente particulado, que chegam aos canais de drenagem e aos rios após

\footnotetext{
${ }^{6}$ Para a classe 3 do CONAMA fica estabelecido que " $a$ turbidez não deve ser superior à 100 UNT em $80 \%$ ou mais de pelo menos 5 amostras mensais colhidas em qualquer mês"
}

as precipitações, pode ser o motivo pelo qual o pH da área seja bastante elevado. Este aspecto foi confirmado por Fritzsons (2003), que acompanhou alterações no $\mathrm{pH}$ na água do rio Capivari ao longo de um intervalo médio de 12 anos, e fez medições próximas e mais distantes das pedreiras.

A alcalinidade também apresentou uma alta variabilidade, mas não foi muito elevada, pois, de acordo com Bittencourt e Hindi (2000), valores entre 30 e $500 \mathrm{mg} / 1$ são bastante aceitáveis. A alcalinidade apresentou correlação negativa com a vazão, evidenciando seu decréscimo com altas vazões, ou seja, pelo efeito da diluição.

Quanto à matéria orgânica, o laboratório da SANEPAR, de onde foram obtidos os dados utilizados neste trabalho, determina a quantidade de oxigênio necessária para oxidar a matéria orgânica presente na amostra, ou quantidade de material redutor existente na água. O método consiste em oxidar a matéria orgânica dissolvida em solução ácida e quente. A oxidação de $1 \mathrm{~g}$ de matéria orgânica requer 1 grama de oxigênio. De acordo com Margalef (1983), este método apresenta apenas um indicativo da quantidade de matéria orgânica facilmente oxidável, pois não oxida a matéria orgânica refratária, necessitando de oxidantes mais enérgicos para isto. Além disto, por este método se decompõe também compostos nitrosos, sulfídricos e clorados dando, às vezes, valores exagerados, sendo a quantidade de matéria orgânica obtida por este método, de acordo com este autor, de 1 a 4 vezes superior que a $\mathrm{DBO}_{5}$.

Quanto às normas, os dados de matéria orgânica são referenciados no $\mathrm{n}^{\circ} 20 / 86$, como $\mathrm{DBO}_{5}$ a $200{ }^{\circ} \mathrm{C}$, ou seja, pela avaliação da matéria orgânica biodegradável presente numa amostra. Assim, a classe 3 poderá apresentar um máximo de 10 equivalentes $\mathrm{em} \mathrm{mg} / 1 \mathrm{em}$ $\mathrm{O}_{2}$. Os IQAs também avaliam a matéria orgânica presente nas águas pela DBO (demanda bioquímica de oxigênio) e DQO (Demanda bioquímica de oxigênio). Assim, comparando estes valores com os valores encontrados nas análises, eles estão dentro do limite aceitável. Ainda como referência, Margalef (1983) cita valores, nos lagos norte americanos, de 2,9 a $39,6 \mathrm{mg} / \mathrm{L}$, o que equivale de 1 a $18 \mathrm{mg} / \mathrm{l}$ de $\mathrm{C}$ (coeficiente de conversão $2,4)$. 
Quanto ao grau de correlação dos parâmetros frente à vazão, estes não se apresentaram muito elevados. A turbidez apresentou maior correlação, como visto na tabela 3. Analisando os dados pontualmente, verifica-se que esta fraca correlação pode ser devido ao fato de que para uma mesma vazão existem valores muito diferentes para os parâmetros, devido à alta dispersão. A seguir os parâmetros serão analisados individualmente.

\begin{abstract}
Alcalinidade
A figura 3 mostra o comportamento da alcalinidade face às alterações de vazão. Observa-se que as vazões fluviométricas mais freqüentes para estes anos foram inferiores a 7 $\mathrm{m}^{3} / \mathrm{s}$. A maior vazão registrada $\left(31,27 \mathrm{~m}^{3} / \mathrm{s}\right)$ não foi plotada para permitir uma melhor visualização da distribuição de pontos. Os valores mais freqüentes de alcalinidade variaram de $80 \mathrm{mg} / \mathrm{l}$ a $110 \mathrm{mg} / \mathrm{l}$.
\end{abstract}

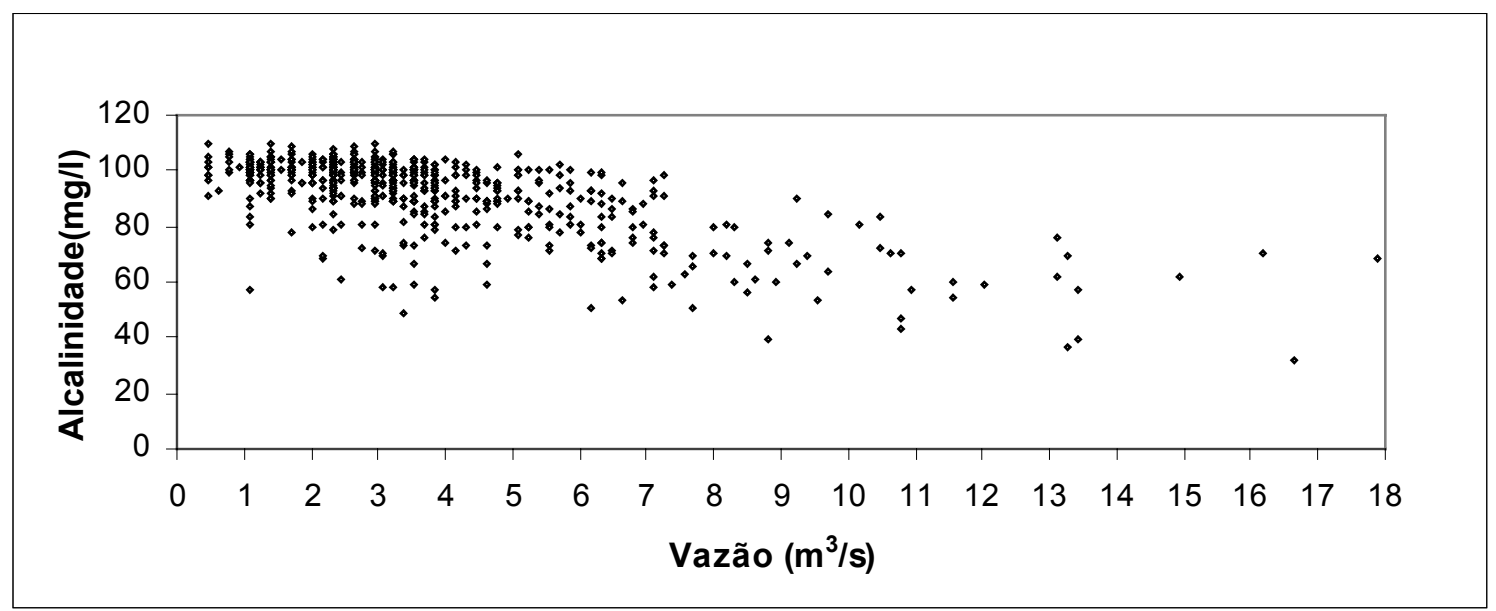

Figura 3: Variação da alcalinidade em função da vazão (rio Capivari, de 1998 a 1999)

Figure 3: Variations of alkalinity as a function of water discharge (Capivari stream, from 1998 to 1999)

$\mathrm{Na}$ tentativa de classificar este comportamento, ajustou-se uma linha de tendência correspondente à equação linear, cujo coeficiente de determinação apresentou um valor de 0,75 , denotando forte relação entre o aumento da vazão e diminuição da alcalinidade. Nota-se nesta figura, que o desvio padrão tende a aumentar com o aumento da vazão, evidenciando uma maior dispersão dos dados.

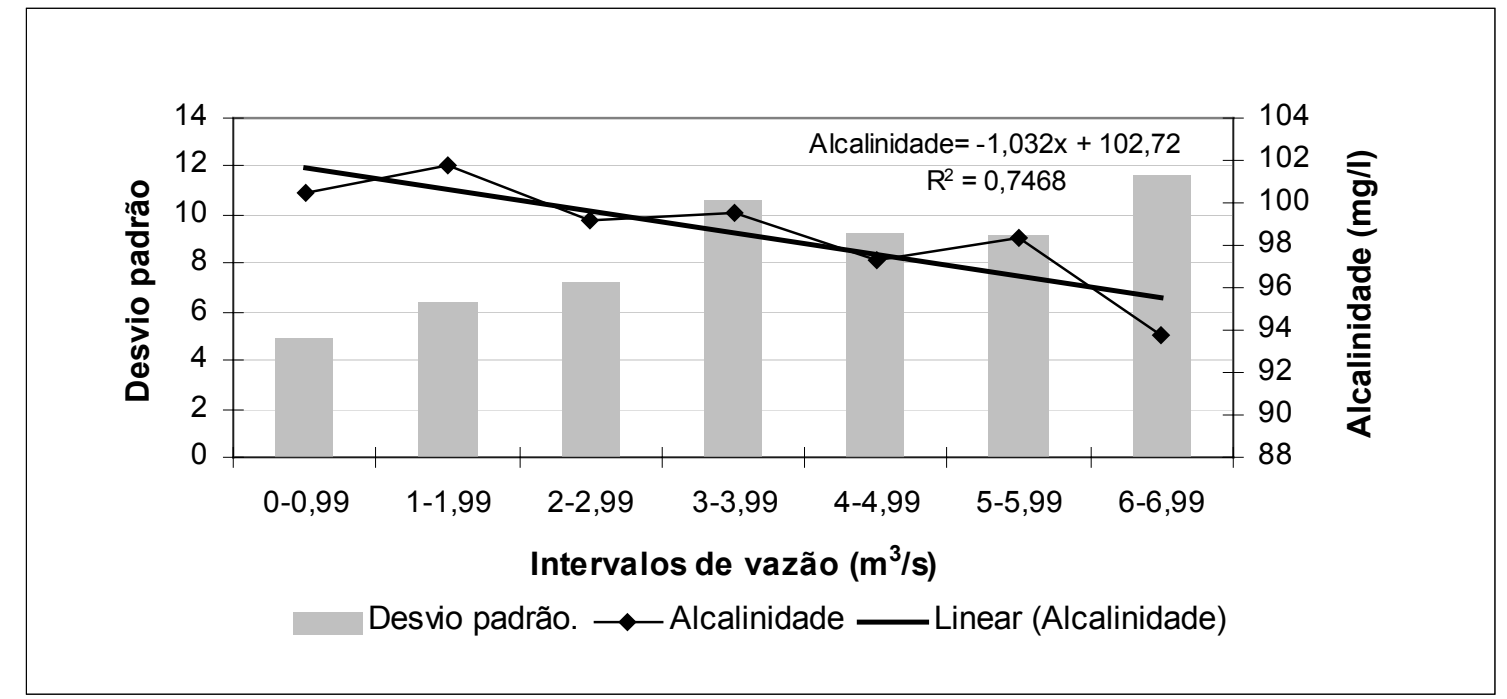

Figura 4: Média da alcalinidade por intervalos de vazão e desvio padrão

Figure 4: Average alkalinity by water discharge intervals and standard deviation 


\section{Potencial Hidrogeniônico}

Quanto ao $\mathrm{pH}$, este se situa na faixa de 7,2 a 9,5, com os valores mais freqüentes entre 7,7 a 8,5. Este valor elevado de $\mathrm{pH}$ encontrado, comparado ao $\mathrm{pH}$ médio de rios brasileiros que drenam substratos mais ácidos e ricos em matéria orgânica, deve-se provavelmente ao substrato cárstico da área.

$\mathrm{Na}$ figura 5 não se observa uma tendência nítida de alteração do $\mathrm{pH}$ com a vazão. Entretanto, a figura 6 apresenta uma tentativa de classificar este comportamento através de uma linha de tendência. Para isto, deslogaritmizou-se o $\mathrm{pH}$, a fim de se trabalhar com uma escala de valores mais próximo da real, e obteve-se a média do $\mathrm{pH}$ por intervalos de vazão de $1 \mathrm{~m}^{3} / \mathrm{s}$, classificados por ordem crescente, procedimento semelhante ao feito para a alcalinidade, que resultou no gráfico apresentado na figura 6 .

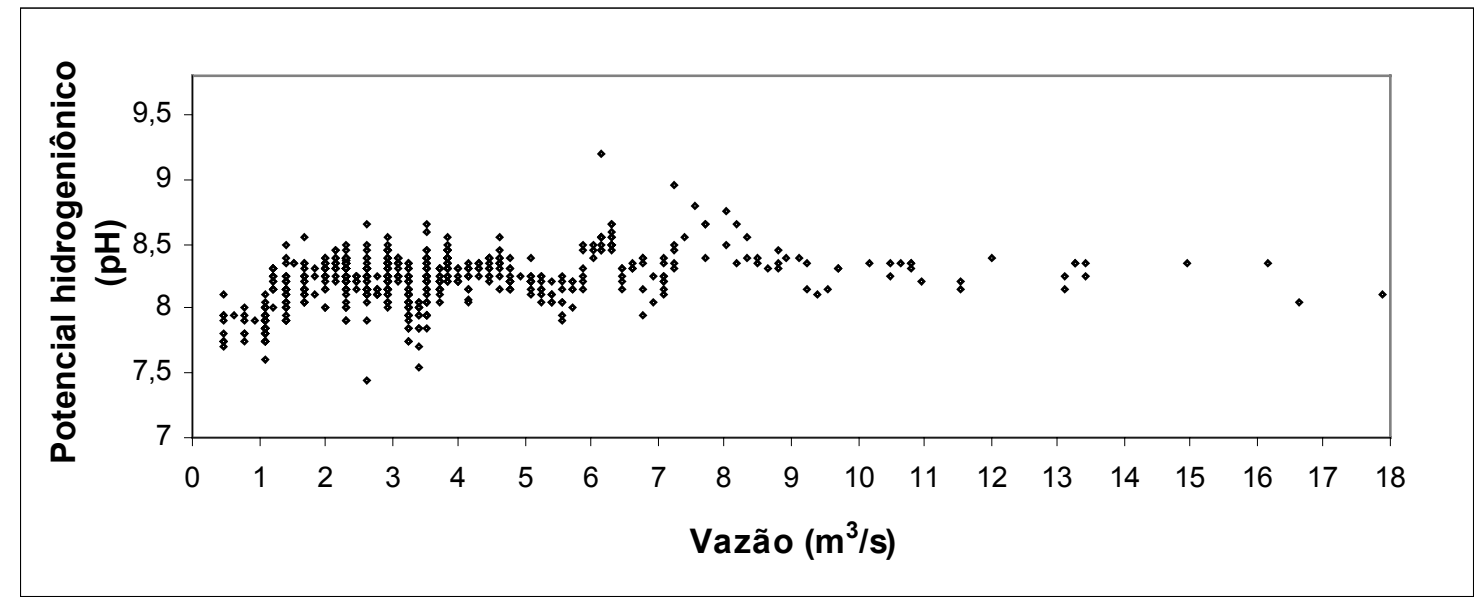

Figura 5: Variação do pH em função da vazão (rio Capivari, de 1998 a 1999)

Figure 5: Variatons of pH as a function of water discharge (Capivari stream, from 1998 to 1999)

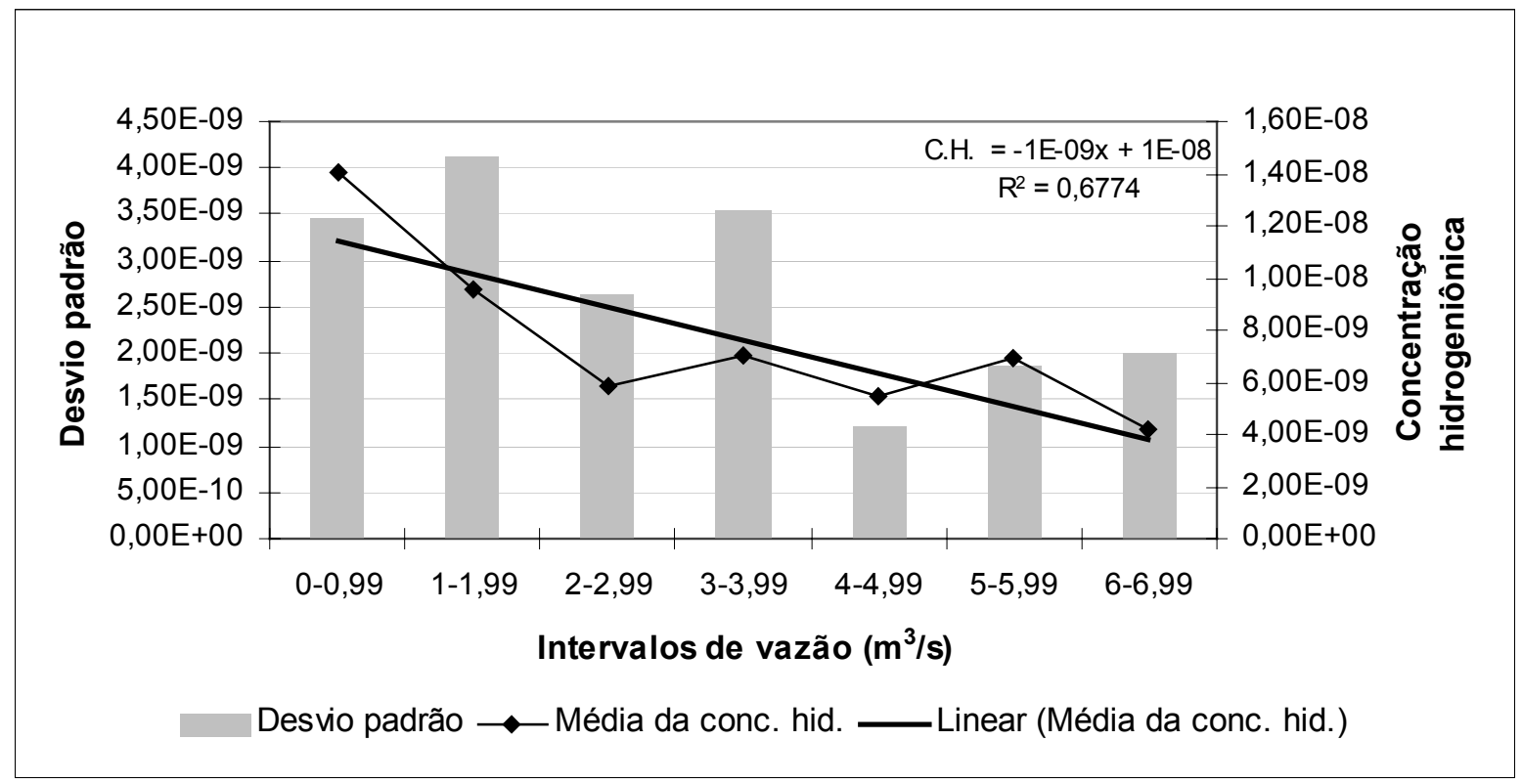

Figura 6: Média da concentração hidrogeniônica por intervalos de vazão e desvio padrão

Figure 6: Average $H+$ concentration for water discharge intervals and standard deviation 
Neste gráfico, pode-se observar que a média da concentração hidrogeniônica para intervalos de vazão apresenta um coeficiente de determinação de 0,68. Assim, para o intervalo considerado, quanto maior a vazão, menor a conc. hidrogeniônica e mais elevado o $\mathrm{pH}$. O desvio padrão também aumenta com o acréscimo da vazão, apresentando, portanto, uma maior dispersão nos dados em vazões maiores.

Entretanto, é difícil estabelecer uma explicação imediata deste padrão de comportamento, pois o $\mathrm{pH}$ constitui um dos parâmetros ambientais mais difíceis de serem interpretados, por sofrer influência de inúmeros fatores, tais como: sólidos e gases dissolvidos, dureza e alcalinidade, temperatura e os fatores bióticos.

\section{Turbidez}

Conforme se pode ver na figura 7, a turbidez tende a se elevar quando a vazão aumenta. Entretanto, observa-se que, comparativamente ao $\mathrm{pH}$ e alcalinidade, a dispersão da turbidez é visualmente muito maior.

Compondo a reta de regressão, da mesma forma que as anteriores, observa-se que a turbidez apresenta uma correlação bastante forte com a vazão, apresentando um coeficiente de determinação 0,93 , como mostra o gráfico da figura 8. Assim, a tendência é: quanto maior a vazão, maior a turbidez.

Quanto ao desvio padrão, ele tende a aumentar com o aumento da vazão, ou seja, com vazões maiores, os valores referentes a turbidez oscilam mais. Isto pode ser explicado, pois as chuvas que causam vazões maiores podem ser muito variáveis, com diferentes graus de erosividade, afetando os terrenos das encostas e das margens. Mesmo porque, após passadas as primeiras chuvas, depois de uma estiagem, o rio, apesar de estar com uma alta vazão, pode apresentar águas mais limpas, uma vez que a entrada de materiais particulados, provenientes das adjacências e da desestabilização de encostas do leito do rio, pode ter ocorrido nas primeiras chuvas.

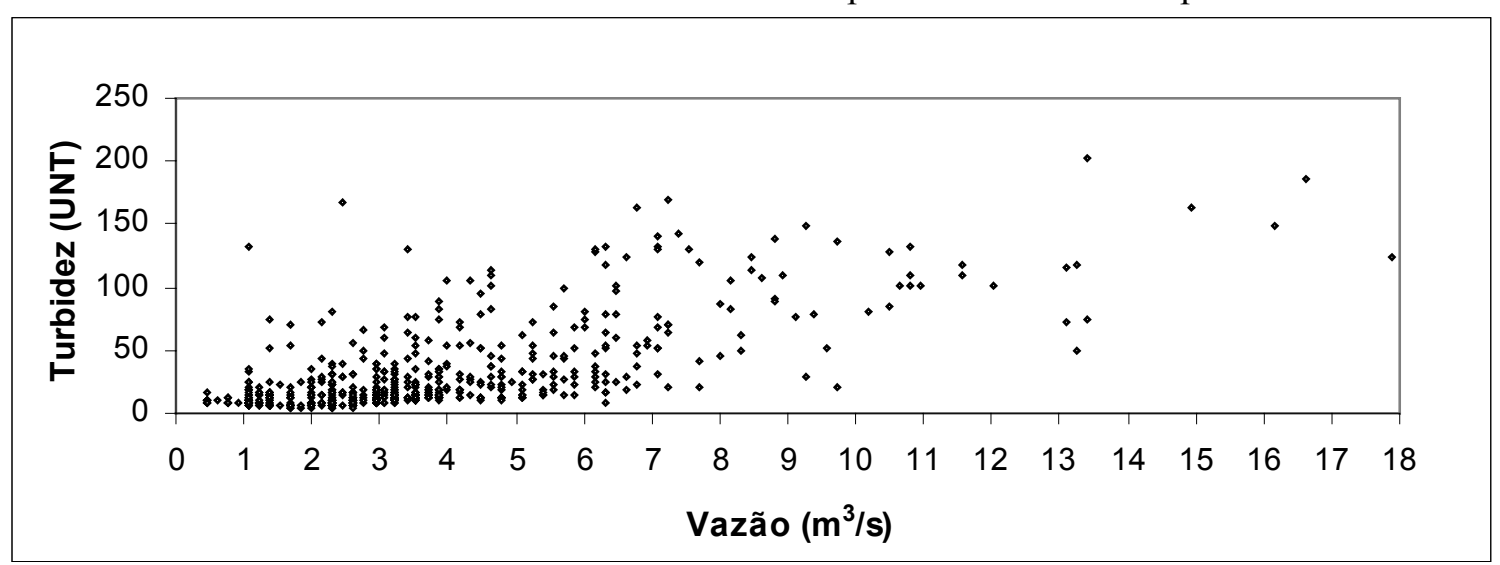

Figura 7: Variação da turbidez em função da vazão (rio Capivari, de 1998 a 1999)

Figure 7: Variations of turbidity as a function of water discharge (Capivari stream, from 1998 to 1999) 


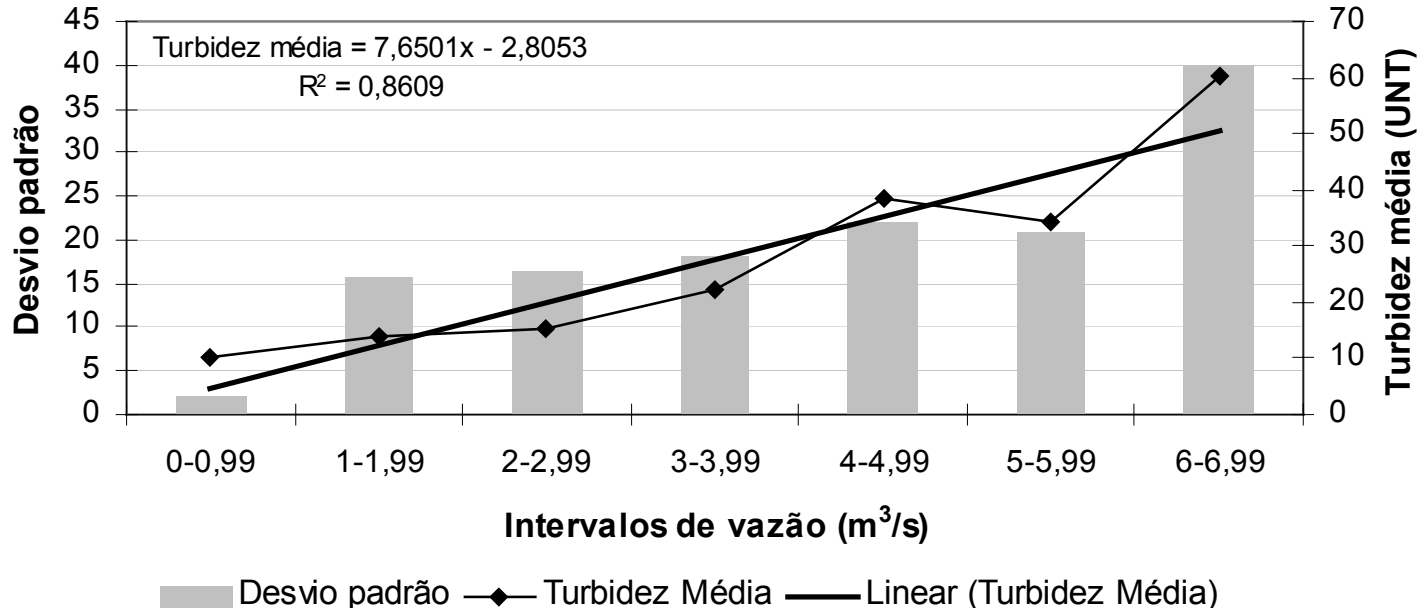

Figura 8: Média da turbidez por intervalos de vazão e desvio padrão

Figure 8: Average turbidity by water discharge intervals and standard deviation

\section{Matéria orgânica}

A relação entre o conteúdo de matéria orgânica no rio Capivari e a vazão pode ser visualizada na figura 9 , onde se observa que a faixa de menor teor de matéria orgânica (entre 2 e $5 \mathrm{mg} / \mathrm{L}$ ) está no intervalo de vazão que vai de 0,5 a $6,0 \mathrm{~m}^{3} / \mathrm{s}$ aproximadamente, e que, em geral, o teor de matéria orgânica se situa entre $2 \mathrm{mg} / \mathrm{L}$ a pouco mais de $12 \mathrm{mg} / \mathrm{L}$. Também fica evidente que nas vazões menores a dispersão é pequena, e nos deflúvios maiores a dispersão aumenta, e que há também uma tendência de aumento do teor da matéria orgânica com o aumento da vazão, como se pode verificar na figura 10. Esta figura mostra que o aumento médio da matéria orgânica frente ao aumento no intervalo de vazão apresenta uma linha de tendência (de regressão) linear, com coeficiente de determinação de 0,96. Assim, um aumento na vazão reflete diretamente no aumento da matéria orgânica. Nota-se, também, a elevação do desvio padrão com o aumento da vazão.

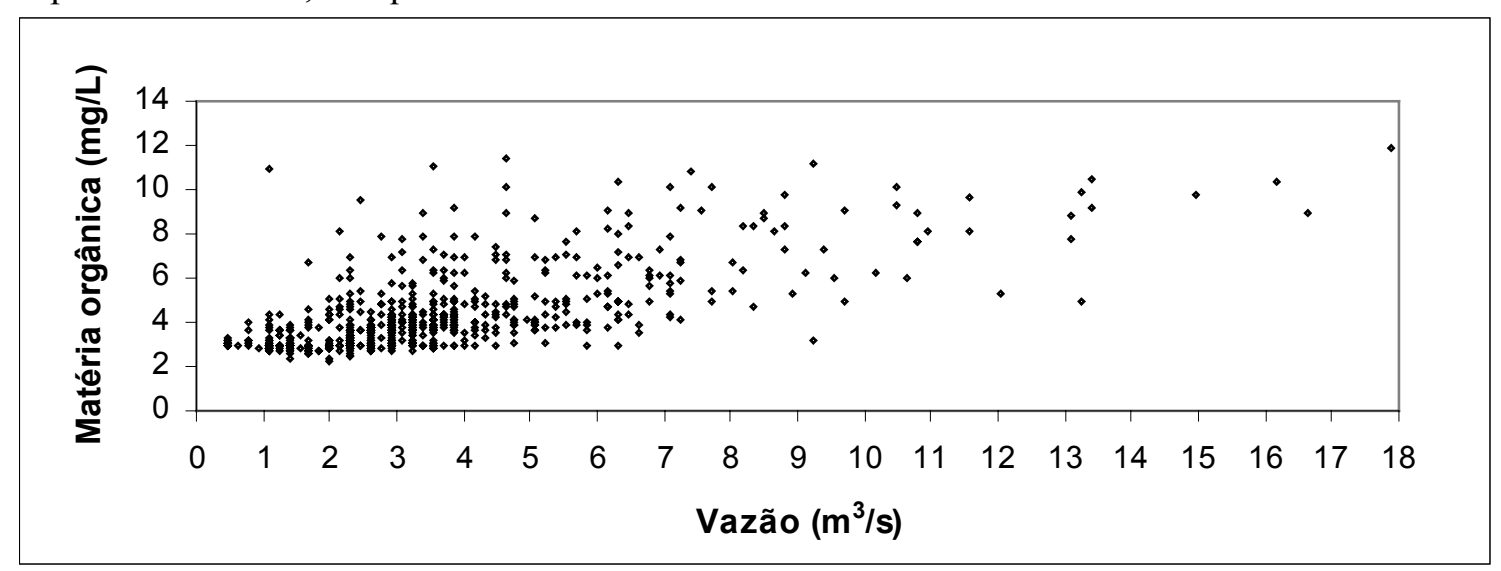

Figura 9: Variação da matéria orgânica em função da vazão (rio Capivari, de 1998 a 1999)

Figure 9: Variations of organic matter as a function of water discharge (Capivari stream, from 1998 to 1999) 


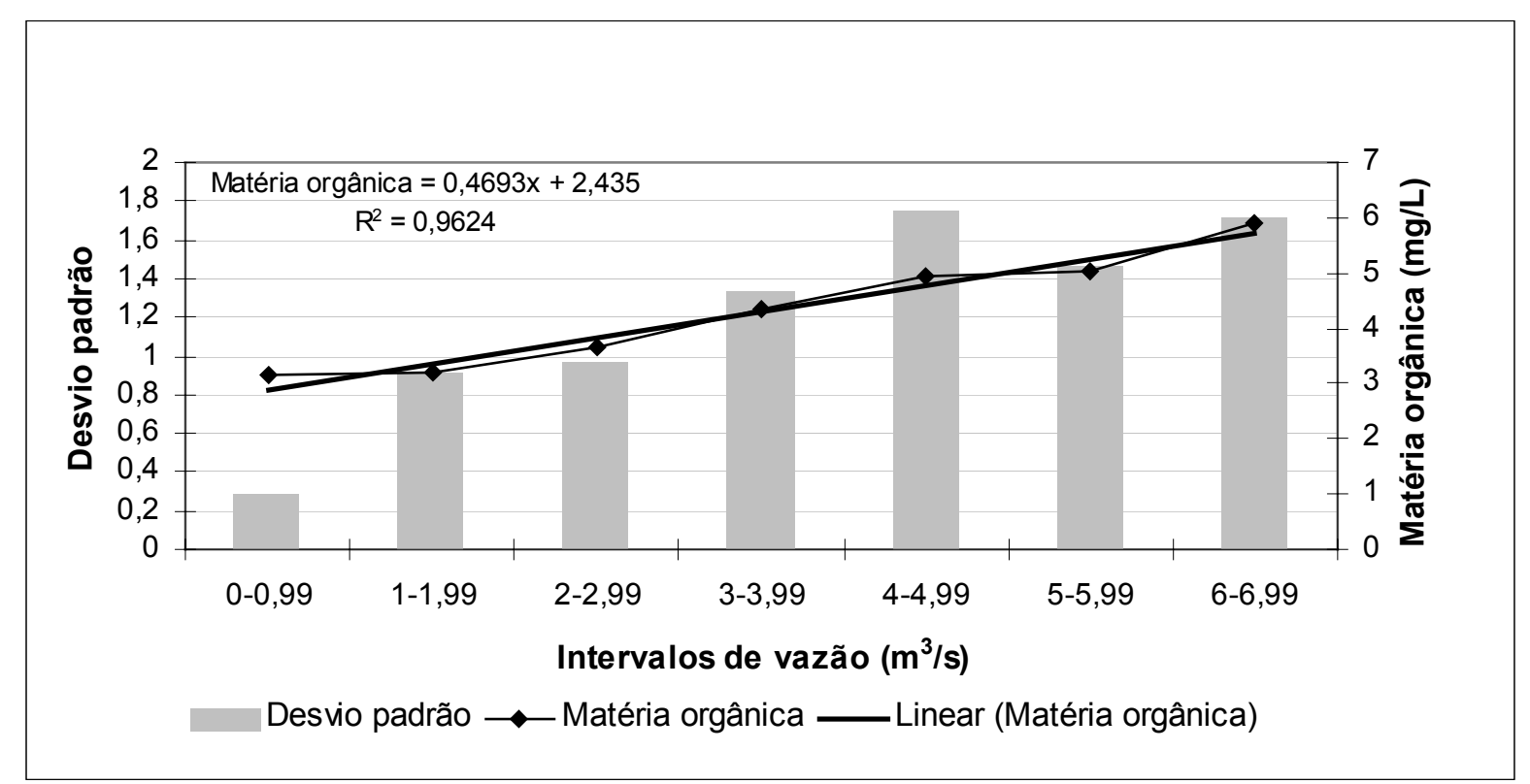

Figura 10: Média da matéria orgânica por intervalos de vazão desvio padrão

Figure 10: Average of the organic matters by water discharge intervals and standard deviation

Este aumento da matéria orgânica com a vazão é justificado pelo carreamento de maiores quantidades de partículas orgânicas do escorrimento superficial e do leito do rio na ocasião de altas vazões. Mesmo em áreas sem interferência humana, isto deve ocorrer, entretanto, em áreas mais artificializadas, onde o ambiente foi mais modificado, em especial nas áreas agrícolas, como ocorre na bacia do Alto Capivari, este comportamento deve ser mais evidente.

\section{Cor}

Quanto à cor, esta apresenta uma tendência de aumento com a elevação de vazão até os níveis estudados, o que pode ser visualizado na figura 11 .

No gráfico 12 observa-se que $\mathrm{o}$ comportamento do parâmetro cor é semelhante ao da turbidez; entretanto, o coeficiente de determinação obtido com a equação linear foi de 0,95 , ou seja, o aumento de vazão está diretamente relacionado ao aumento médio na cor. É natural que a cor, estando relacionada aos sedimentos, argilas e materiais orgânicos dissolvidos, se eleve com o aumento da vazão. Quanto ao gráfico de dispersão, observa-se que ele é muito semelhante ao da turbidez.

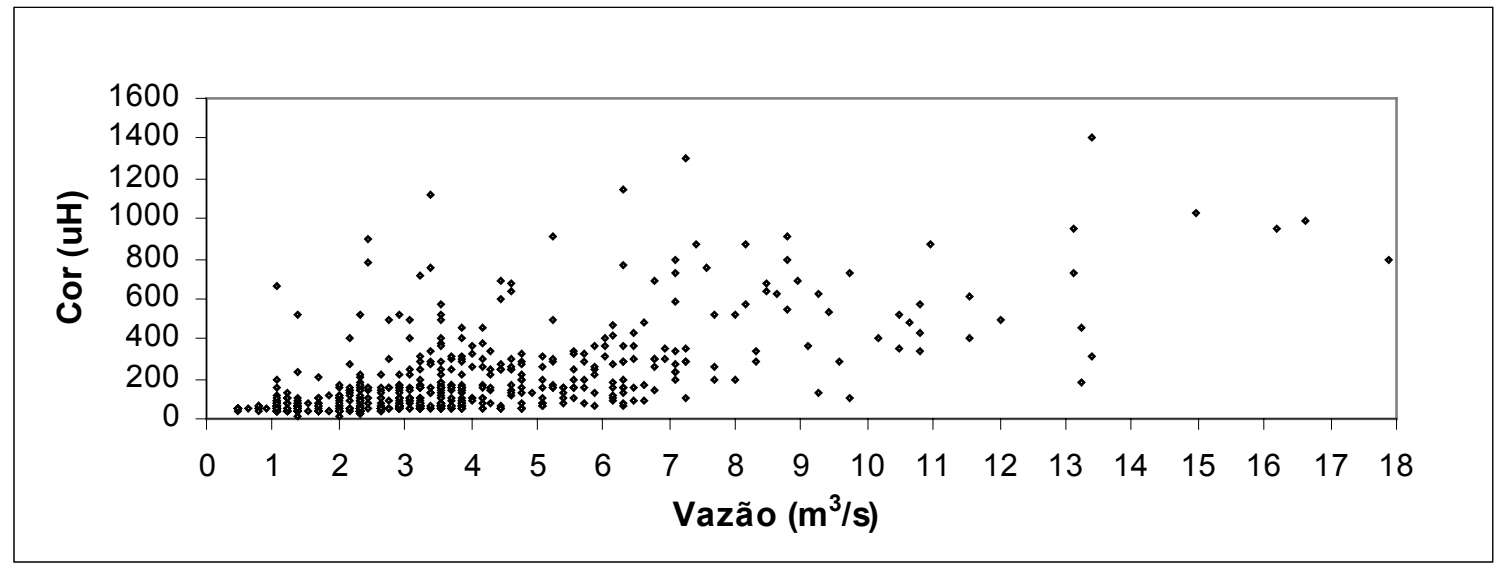

Figura 11: Variação da cor real em função da vazão (rio Capivari, de 1998 e 1999)

Figure 11: Variations of real color as a function of water discharge (Capivari stream, from 1998 to 1999) 


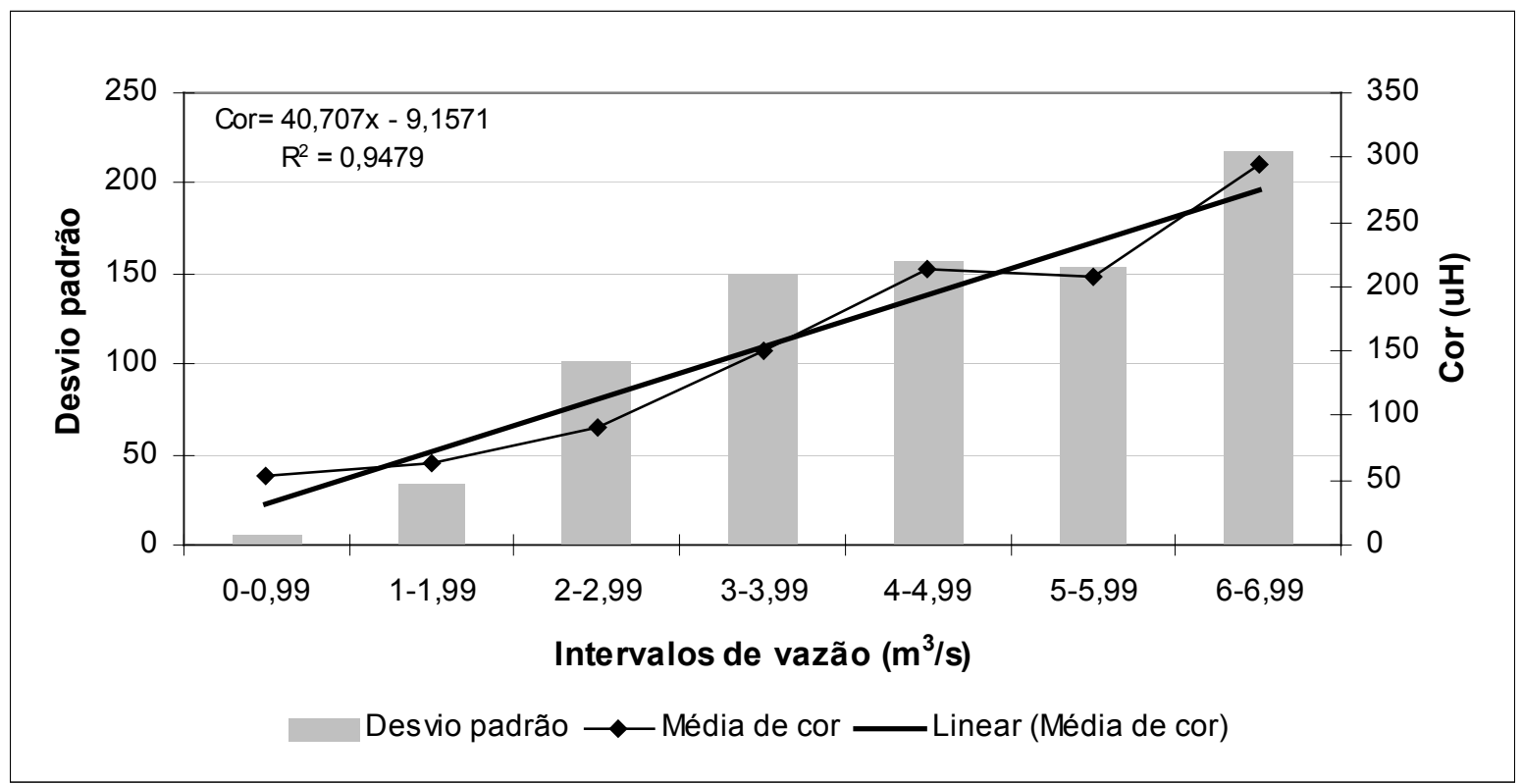

Figura 12: Média da cor por intervalos de vazão e desvio padrão

Figure 12: Average of the color by water discharge intervals and standard deviation

\section{CONCLUSÃO}

Os valores quantitativos de qualidade de água obtidos na análise estatística descritiva, tais como média, mediana e desvio padrão, evidenciam que rio o Capivari, no trecho estudado, apresenta altos valores de turbidez média e cor média, em níveis que podem restringir suas águas para $\mathrm{o}$ abastecimento.

Os valores dos parâmetros também evidenciaram um desajuste ambiental refletido na alteração crescente da qualidade das águas com a alteração do deflúvio. Em ambientes mais protegidos, isto não ocorre desta forma, havendo um maior tamponamento do sistema. A precipitação e conseqüente alteração na vazão desencadeia processos erosivos que aumentam a turbidez, a cor e o teor de matéria orgânica nas águas, uma vez que durante as precipitações predominam as entradas de água de escoamento superficial.

A análise da média do valor de cada parâmetro dentro de intervalos de vazão foi um artifício utilizado que possibilitou a obtenção de uma tendência do comportamento do parâmetro, a qual não foi nítida, considerandose apenas valores absolutos. Entretanto, é necessário observar o desvio padrão de cada intervalo, pois para todos os parâmetros, ele foi menor em baixas vazões e maior em deflúvio mais alto.

Estas tendências observadas neste trabalho são condizentes com as normalmente verificadas em literatura. Com uma série de dados mais longa, talvez fosse possível fazer predições mais detalhadas no comportamento médio destes parâmetros, relacionando-os as variações menores de intervalos de vazão e possibilitando um melhor ajuste nas retas, com equações mais adequadas a cada parâmetro. Neste trabalho, apenas se utilizou a equação linear.

Este conhecimento da influência da alteração da vazão no comportamento da qualidade de águas poderia ser útil, não somente para as estações de tratamento, que necessitam tratar águas de qualidade altamente variáveis, como foi evidenciado neste trabalho, mas também no âmbito de estudos ambientais, utilizando a qualidade das águas como importante meio de diagnóstico da integridade ambiental dos rios e de seu entorno, ou seja, de sua bacia hidrográfica.

\section{AGRADECIMENTOS}

Os autores desejam expressar seus agradecimentos à SANEPAR, que proporcionou os dados básicos para a realização deste trabalho. 


\section{REFERÊNCIAS}

ALLAN, David. Stream Ecology: Structure and function of running waters. London: Chapman \& Hall, 1995.

ARCOVA, F. C. , CICCO, V de. Pesquisas em microbacias hidrográficas no laboratório de hidrologia florestal Walter Emmerick, Cunha, SP. II- Qualidade de água e Geoquímica. In: I Fórum Geo-Bio-Hidrologia. Anais. 13 a 15 de outubro de 1998. Curitiba. p. 201 a 210.

BITTENCOURT, A V L. \& HINDI, E.C. Tópicos de hidroquímica in: 3er Curso Sudamericano sobre Evalucion y Vulnerabilidad de Acuíferos. Asunción Paraguay. ITAIPÚ BINACIONAL; Organization de Los Estados Americanos. Cap 3, 211p. 2000.

BRANCO, S. M., ROCHA, A. A Elementos de Ciências do Ambiente. São Paulo: CETESB / ASCETESB. 1987. 206p.

CHAPMAN, D. Water Quality Assessment. London: Chapman \& Hall Ltda., 1992. 585p.

CONAMA. Resoluções do CONAMA, 1984 / 91. 4. ed. ver. e ampl., Brasília : IBAMA,. 245 p.1992.

FRITZSONS, E. Avaliação temporal da qualidade de água como diagnóstico do uso e ocupação das terras na bacia do Alto Capivari, Região Cárstica Curitibana. Curitiba: UFPR, 2003, 190 p. - Pr. (Tese Doutorado em Engenharia Florestal).
JICA - JAPAN INTERNATIONAL COOPERATION AGENCY. The master plan study on the utilization of water resources in Paraná state in the Federative Republic of Brazil. Tokio: JICA. v. J: Soil and erosion Forest. 1995. Relatório Técnico.

MAACK, R. Geografia Física do Estado do Paraná. 2 ed. Rio de Janeiro: J. Olympio. 168p. 1981.

MARGALEF, R. Limnologia. 1009p 1983. Barcelona: Omega.

MEYBECK, M., FRIEDRICH, G., THOMAS, R; CHAPMAN, D. Rivers. In: Chapman. D. Water Quality Assessment. London: Chapman \& Hall Ltd. 1992. p. 239-316.

SOUZA, E. R. de. Alterações físico-químicas no deflúvio de três sub-bacias hidrográficas decorrentes da atividade agrícola. Lavras: UFLA, 1996, 91p. (Dissertação - Mestrado em Engenharia Florestal)

SUDERHSA. Qualidade das águas interiores do Estado do Paraná. 1987-1995. SUDERHSA. 257p. 1997. 